\title{
Development of Indigenous Iron-Coated Pottery Granules for Arsenic (V) Removal from Groundwater
}

\author{
Khadija Qureshi ${ }^{1,}{ }^{*}$, Kashif Hussain Mangi ${ }^{2,3}$, Zulfiqar Ali Solangi ${ }^{1}$, Zulfiqar Ali Bhatti ${ }^{1}$, Mukhtiar Ali ${ }^{1}$, \\ Sikandar Almani ${ }^{1}$
}

${ }^{1}$ Department of Chemical Engineering, MUET, Jamshoro, Pakistan.

${ }^{2}$ Department of Chemical Engineering, QUEST, Nawabshah, Pakistan

${ }^{3}$ GEPEA Laboratory, University of Nantes, France

${ }^{*}$ Corresponding author: khadija.qureshi@faculty.muet.edu.pk

\begin{abstract}
Arsenic is a carcinogenic element capable to get into water bodies and drinking water supplies from natural deposits and industrial practices. Its presence in drinking underground water is highly toxic to human health. The study is focused on the development of indigenous Iron-Coated Pottery Granules (ICPG) to remove As from groundwater of Hala City. The developed ICPG was agitated with local clay white flour and water. A low-cost adsorbent namely ICPG was synthesized for the expulsion of $A s$ from underground water. The ICGP was characterized with SEM and FTIR techniques. Furthermore, the impact of physical parameters including adsorbate concentration, dosage, mixing time, $\mathrm{pH}$, and contact time on $A s$ removal efficiency was investigated in batch experiments. The maximum removal efficiency was achieved with an adsorbent dosage of 0.5 grams at $\mathrm{pH}=7$ for a contact time of 90 minutes when agitated at a speed of $150 \mathrm{r} / \mathrm{min}$. The arsenic removal efficiency was found highly dependent on contact time increase and optimum $\mathrm{pH}$ (maximum removal achieved at strong adsorption of $A s$ at $\mathrm{pH} 4-7$ ), however, the rise of adsorbate concentration resulted in the decrement in the efficiency after certain range. Batch adsorption study of underground water sample collected from Hala, Sindh, Pakistan was performed with satisfactory results, i.e. 94 arsenic removal from water. All the water samples were analyzed through atomic absorption Spectrophotometer. The investigation has indicated that ICPG is an exceptionally favourable material for As removal from drinking underground water and can be applied to handle the arsenic issue in most of the regions of Sindh province.
\end{abstract}

Keywords-Drinking water, indigenous pottery granules, arsenic removal, batch adsorption study

\section{Introduction}

A RSENIC is a lethal and cancer-causing element and WHO has considered it a priority issue among the poisonous substances [1]. Arsenic-rich rocks are the primary sources of $A s$ in ground water through which the water has permeated. Mining and industrial activities also contribute in receiving $A s$ in different regions [2]. Anthropogenic and industrial activities including mining, combustion of fossil fuels, agriculture and industrial waste discharges also contribute to arsenic contamination in potable water. A large number of individuals are enduring with skin diseases, cancers and other

ISSN: 2523-0379 (Online), ISSN: 1605-8607 (Print)

DOI: $10.52584 / Q R J .1802 .18$

This is an open access article published by Quaid-e-Awam University of Engineering Science \& Technology, Nawabshah, Pakistan under CC BY 4.0 International License. relevant infections because of the utilization of $A s$ contaminated groundwater around the world, mostly China, India and Bangladesh, etc [3]. WHO prescribed safe permissible limit of $A s$ in potable water is $10 \mathrm{ppb}$; whereas, that of EPA Pakistan is $50 \mathrm{ppb}$. Membrane separation, coagulation, Sorptive media filtration and adsorption are the most efficient technologies adopted to eliminate $A s$ from drinking water sources [4][5]. Among all the methods, adsorption is one of the economical and easily applicable techniques [6]. Filtration, precipitation and co-precipitation are three basic mechanisms employed for the removal of $A s$ from water through coagulation process [7][8]. At molecular level, Sorptive media filtration technique is used to mitigate dissolved $A s$ by addition of sorptive media [7]. Iron-coated pottery granules (IGPC) based method has been described for As expulsion 


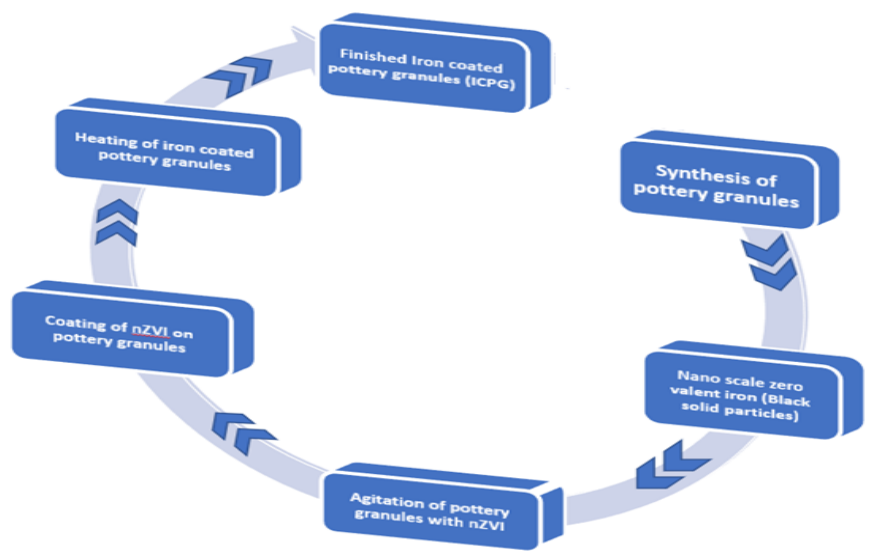

Fig. 1: Methodological steps for ICGP development

from potable water [9][10]. The main objectives of this study are: (a) to develop and synthesize ironcoated pottery granules through indigenous sand, (b) cCharacterization of ICPG by SEM and FTIR techniques, (c) to acknowledge the effect of adsorbent dosage, $\mathrm{pH}$, contact time and initial adsorbate conc. on $A s$ expulsion efficiency.

\section{Material \& Methods}

\subsection{Synthesis of Iron-Coated Pottery Granules}

All analytical grade chemicals glassware were cleaned and soaked in $10 \% \mathrm{HCl}$, and properly washed with de-ionized water. Arsenite solution (100 ppm) was prepared by dissolving potassium arsenate monobasic $\left(\mathrm{AsH}_{2} \mathrm{KO}_{4}\right)$ in distilled water, and one drop of nitric acid (HNO3) was used for preservation of synthesized solution. The detailed development processes of ICGP is described in Figure 1, where important stages are involved in the synthesis of ICPG media: (1) firstly, pottery granules were produced by the adequate mixture of local clay (kaolinite, 97\% pure), white flour (carbon source material) and water and heated in an oven first at $110^{\circ} \mathrm{C}$ and then further to $500^{\circ} \mathrm{C}$ for 3 hours, (2) synthesis of zero-valent iron was accomplished by mixing iron chloride hexahydrate solution with sodium borohydride solution resulting black solid particles, which were then washed with ethanol, dried and attached to pottery granules (3:7) with continuous stirring. Iron powder and granules were mixed for 20 minutes and put into an aluminum sheet, and (3) iron-coated pottery granules were heated again, first at $80^{\circ} \mathrm{C}$ and then at $500^{\circ} \mathrm{C}$ for 1 hour. Granules were observed to be strengthened by this re-firing process.

\subsection{Characterization}

The iron-coated pottery granule (ICPG) was characterized by different analytical instruments. Scanning electron microscope (JEOL, JSM-6380LV, USA) measured surface morphology of the adsorbent where surface characteristics of the material with an accelerated voltage of $5 \mathrm{kV}$ and 1,000× magnification. To determine different functional groups of ICPG, FTIR spectrometer was utilized. The FTIR spectra were noted in the wavelength range of 4000-500 $\mathrm{cm}^{-1}$. Atomic Absorption Spectroscopy (AAnalyst700, PerkinElmer, USA) was utilized for the determination of arsenic $[A s$ $(\mathrm{V})]$ in the solution. China clay (DRK-7) was used as a basic constitute for the synthesis of the adsorbent. FTIR (PerkinElmer, USA) technique was also utilized to deduce internal bindings of $A s$ by the adsorbent.

\subsection{Batch Adsorption Experiments}

The adsorption features of arsenic onto ICPG were considered under equilibrium and dynamic conditions. All the batch experiments were conducted in a 100 ml flask to examine the As removal efficiency of ICPG media while considering the wide ranges of each physical parameter's adsorbent dosage ( 0.25 to 1.5 grams $/ 50 \mathrm{ml}), \mathrm{pH}(2-10)$, contact time (0.5 to 02 hours), and mixing speed of $150 \mathrm{r} / \mathrm{min}$ at a regulated room temperature of $24^{\circ} \mathrm{C} \pm 2^{\circ} \mathrm{C}$ [11].

Each sample was further processed to gravity filtration process by using normal lab filters and then the residual concentration of $A s$ for all samples were analyzed using atomic absorption spectrometer.

\section{Results}

This section presents the results of this study.

\subsection{Scanning Electron Microscope (SEM)}

The SEM test of ICPG, i.e., unused iron coated pottery granules (before adsorption) was carried at a magnification of $250 \times$ and $100 \times$ (Figure $2 \mathrm{a}$ ) in order to relate with exhausted ICPG adsorption (by $A S$ ) at a magnification of $250 \times$ and $100 \times$ (Figure 2b).

Figure $2 \mathrm{a}$ and Figure $2 \mathrm{~b}$ relate the surface structures of unused ICPG (before the arsenic test) with exhausted ICPG (after arsenic test) at a magnification of $250 \times$ and $100 \times$ respectively. Figure $2 \mathrm{a}$ represents that a rough surface has been build up for $A s$ adsorption by the iron and clay substrate on ICPG surfaces. The smooth surface structure appears to some extent due to extensive flow by contact during arsenic adsorption (Figure 2b). Arsenic adsorption takes place at the surface media, apparently including inner surface areas of the media pores. 


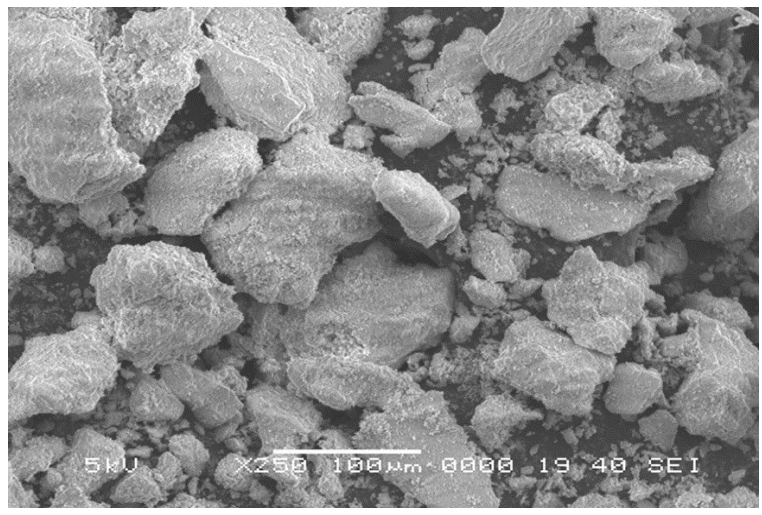

(a)

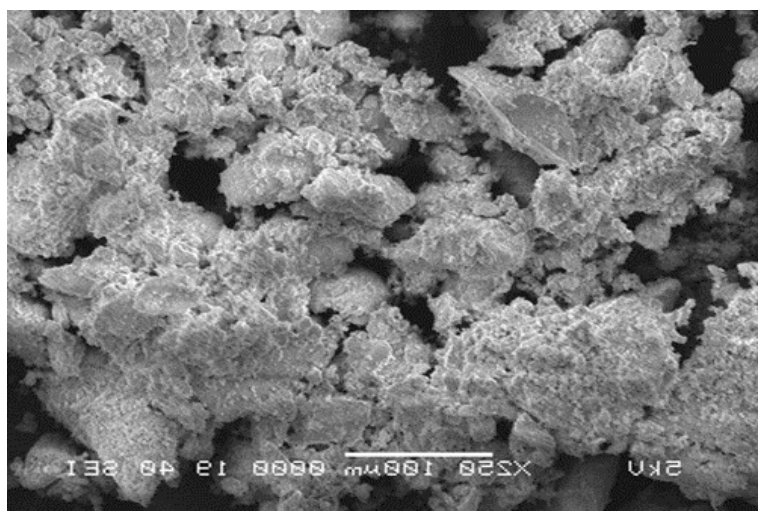

(b)

Fig. 2: SEM of ICPG (a) before and (b) after adsorption of $A s$

\subsection{Fourier-Transform Infrared Spectroscopy (FTIR)}

In order to analyze different functional groups of $A s$ (before and after) adsorption, the FTIR bands of ICPG was measured (Figure 3a and Figure 3b). The existence of band at $3414.58 \mathrm{~cm}^{-1}$ is because of bonded $\mathrm{OH}$ groups, which specifies the occurrence of water crystallization. The band at $2882.01 \mathrm{~cm}^{-1}$ is the result of amide group, but after adsorption, it is shifted to $2994.19 \mathrm{~cm}^{-1}$ by means of little broadening. The band at $1612.42 \mathrm{~cm}^{-1}$ is because of the presence of $C=O$ stretching groups available information [12].

\subsection{Batch adsorption studies}

\subsubsection{Effect of Adsorbent Dose}

Adsorbent dosage has a significant effect on arsenic removal. Weights of adsorbent were varied from (0.1 to $1.0 \mathrm{~g} / 50 \mathrm{ml})$. Each flask of different dose in $50 \mathrm{ml}$ solution with $50 \mathrm{ppb}$ initial concentration adjusted to required $\mathrm{pH} 7$ was shaken in agitator (MIDGET STIRRER, MZ-800H) with $150 \mathrm{rpm}$ at $25^{\circ} \mathrm{C} \pm 1^{\circ}$ for required incubation time $(90 \mathrm{~min})$. The results

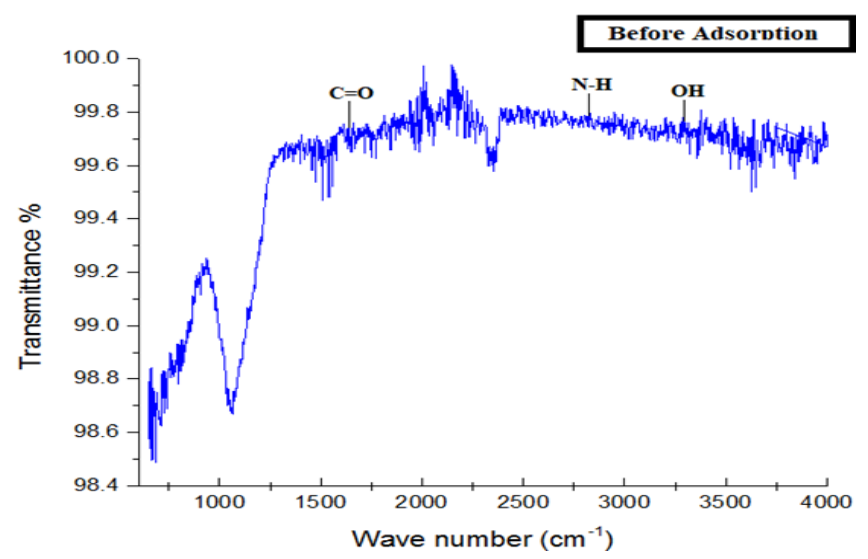

Fig. 3a: FTIR spectra of ICPG before adsorption

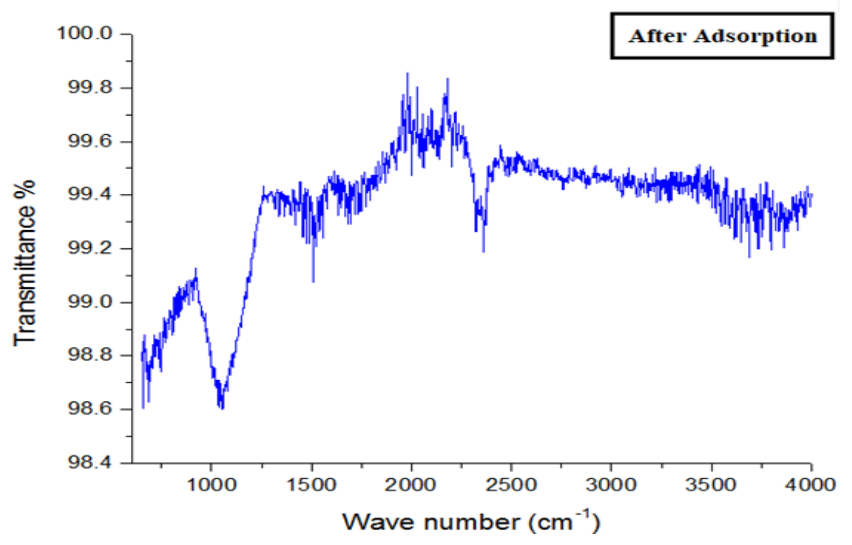

Fig. 3b: FTIR spectra of ICPG After adsorption

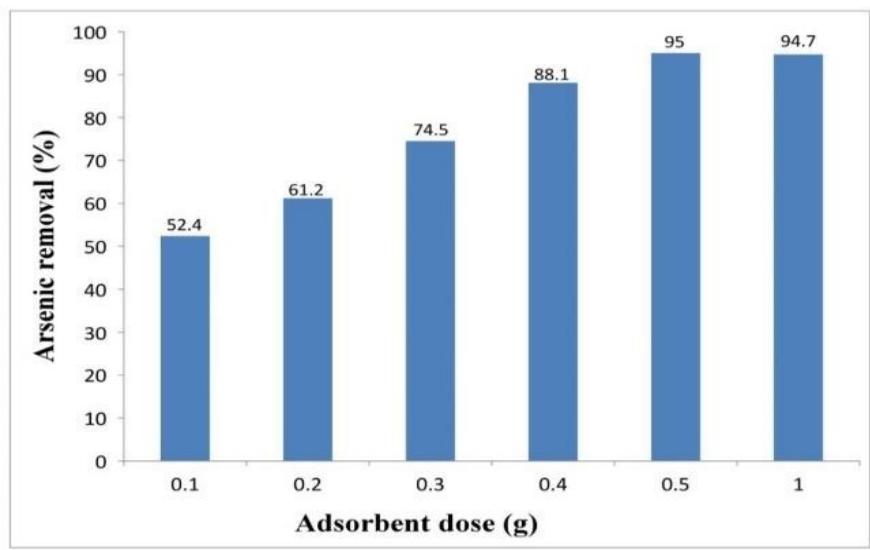

Fig. 4: Effect of adsorbent dose on arsenic removal efficiency 


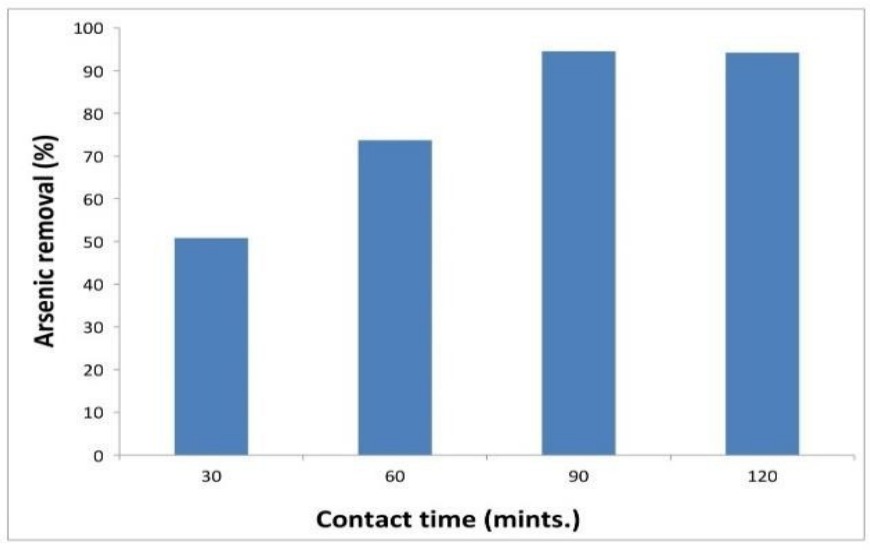

Fig. 5: Effect of contact time on the adsorption of $A s$

revealed that maximum adsorption of $A s$ by ICPG was $95 \%$ with $0.5 \mathrm{~g} / 50 \mathrm{ml}$ of the adsorbent as shown in Figure 4. It could be seen in Figure 4 that $A s$ expulsion efficiency significantly increased with the addition of adsorbent dosage. The change in dose from 0.1 to $0.5 \mathrm{~g} / 50 \mathrm{ml}$ brought about an increment from 52.4 to $95 \%$ in adsorption of As. This might be because of the more availability of the interchangeable sites at elevated concentrations of the adsorbent [13][14]. No substantial growth in As expulsion efficiency was seen on further addition of adsorbent dosages from $0.5 \mathrm{~g}$ onwards.

\subsubsection{Effect of Contact Time}

The impact of contact time on arsenic expulsion efficiency was calculated in the range of $30 \mathrm{~min}$ to 120 min at $\mathrm{pH}=7$ and adsorbent dose of 0.5 grams. A weighed amount of ICPG was utilized in $50 \mathrm{ppb}$ arsenic and agitated in a shaker at $150 \mathrm{r} / \mathrm{min}$ at varied time intervals of 30,60, 90 and 120 mints. It was found that As adsorption attained a maximum value (i.e. 94.5\%) after $90 \mathrm{~min}$, after which no considerable variation was detected. The fast adsorption rate at early stage is due to greater presence of active binding sites on the adsorbent surface 15 . Therefore, a 90 minutes contact time for ICPG was satisfactory to attain equilibrium.

\subsubsection{Effect of $\mathrm{pH}$}

To observe the impact of $\mathrm{pH}$ on arsenic removal efficiency, the adsorption behaviour of the ICPG was assessed in various arrangements of analyses at varying $\mathrm{pH}$ of $2,4,6,7,8$ and 10 . It was observed that $A s$ adsorption is good in limits between 4.07.0 and maximum at $\mathrm{pH}=7.0(92.7 \%)$, and it was considered an ideal $\mathrm{pH}$ state for more experimentation [16]. The arsenic removal efficiency was seen to be decreasing sharply at higher $\mathrm{pH}$ range, i.e. at $\mathrm{pH}=8.0$

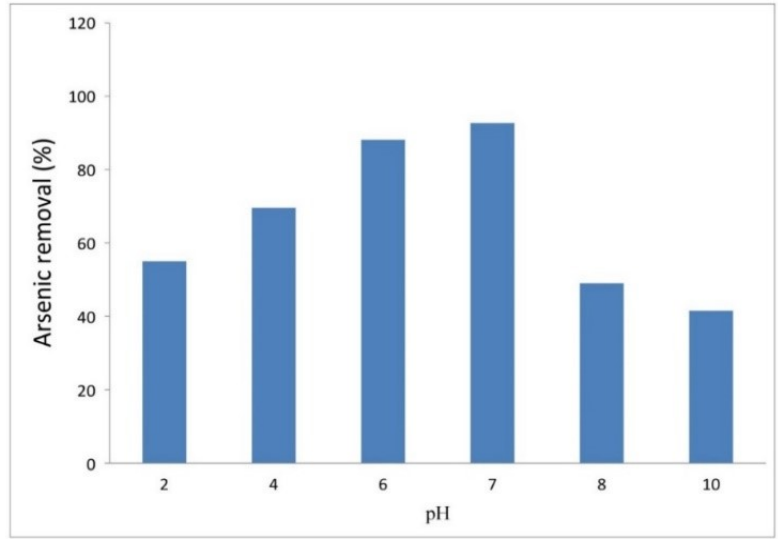

Fig. 6: Effect of pH on Arsenic removal efficiency

and $\mathrm{pH}=10.0$. The reduction in Arsenic removal with increasing $\mathrm{pH}$ might be because (i) a huge quantity of hydroxyl ions in water try to compete for active sites alkaline $\mathrm{pH}$, or (ii) the above-achieved $\mathrm{pH}$ demonstrates a decent concurrence with zero-point surface charge [17].

\subsubsection{Effect of Initial Arsenic (Adsorbate) Concentra- tion}

The adsorption behaviour of $A s$ was analyzed in $A s$ concentration limit of $25-100 \mathrm{ppb}$ at $\mathrm{pH}=7.0$. Essentially, the removal percentage of $A s$ on ICPG adsorbent was first enhanced with increasing the initial amount of $A s$ attaining the optimal level of $95.0 \%$ at $50 \mathrm{ppb}$ As concentration. From there, the level of evacuation demonstrated a little decline as shown in Figure 7.

\subsection{Study on Real Water Sample (Hala City) for As Expulsion}

For the purpose of evaluating the arsenic removal results of the real sample, real sample water (groundwater) was collected from Hala city, Sindh, Pakistan and its arsenic contamination was tested and found to be $200 \mathrm{ppb}$. After the atomic absorption spectrometer test, the result revealed that As removal is $94 \%$ by employing optimized parameters found in the current study.

\subsection{Comparison With the Literature}

The results obtained in the presented study are also compared with other studies in the literature (Figure 8). While the operating parameters and the type of adsorbent are different in other studies, but the removal 


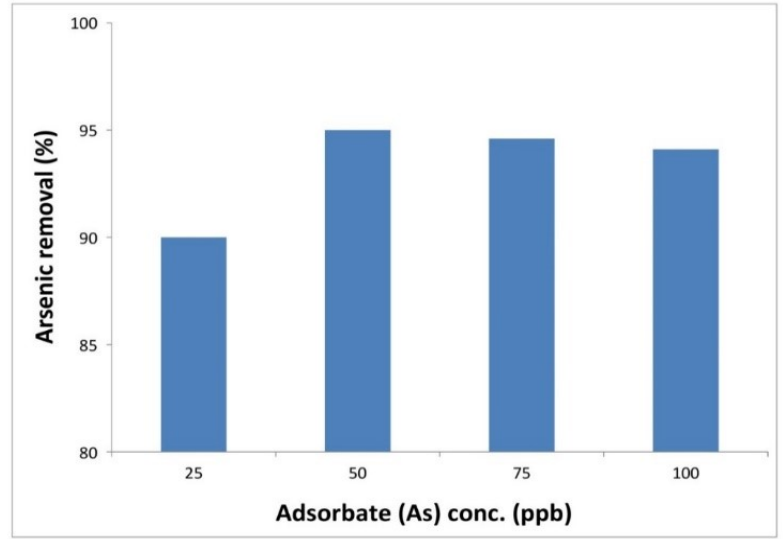

Fig. 7: Effect of initial arsenic concentration on $A s$ adsorption by ICPG

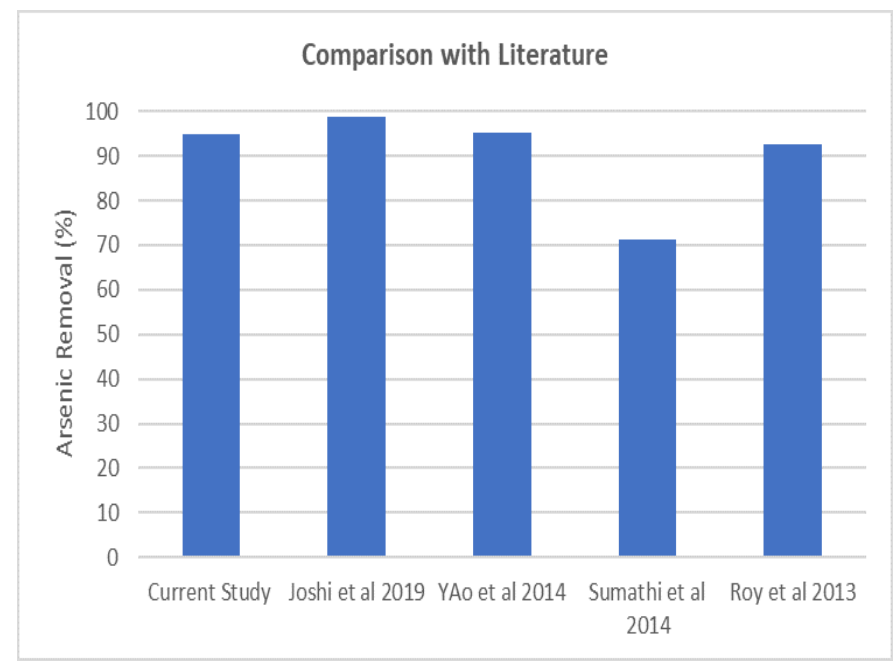

Fig. 8: Comparison of current study with the studies presented in literature

efficiency of adsorbent developed in our study is highly efficient compared to others.

\section{Conclusions \& Recommendations}

Iron coated pottery granule has been observed as an effective adsorbent for $A s$ removal from drinking water. There are several benefits of ICPG media such as the cost-effective process makes ICPG media a great competent adsorbent for removing $A s$ at ordinary $\mathrm{pH}$, and its arsenic adsorption competency utilizing $\mathrm{F}(0)$ coated on the sample. The qualitative results from SEM and FTIR assured the As adsorption. Batch adsorption experiments showed that the maximum $A s$ removal percentage was $95 \%$ under ideal conditions of adsorbent dosage: 0.5 grams $/ 50 \mathrm{ml}, \mathrm{pH}=7$ of the solution, agitation time $=90$ mints and agitation speed $=150 \mathrm{r} / \mathrm{min}$. From this research, it is evidently concluded that ICPG sample can be appropriately used for $A s$ expulsion from portable water.

This work can be extended by using ICPG as an adsorbent for the expulsion of arsenic and other contaminated minerals from groundwater, and similarly in the removal of heavy metal ions from wastewater. Column studies can also be carried out to determine the efficiency of the adsorbent for commercial and industrial purposes. By keeping in view the current scenario of arsenic-contaminated water problems around the globe, the usage of this adsorbent is not up to that mark. Therefore, more studies and exploration of this adsorbent are needed. By removing other contaminants from potable water, in this way, the scope of this adsorbent can be extended.

\section{References}

[1] S. L. Lo, H. Te Jeng, and C. H. Lai, "Characteristics and adsorption properties of iron-coated sand," Water Sci. Technol., vol. 35, no. 7, pp. 63-70, 1997.

[2] J. C. Ng, J. Wang, and A. Shraim, "A global health problem caused by arsenic from natural sources," Chemosphere, vol. 52, no. 9, pp. 1353-1359, 2003.

[3] A. L. Lindberg et al., "Arsenic exposure in Hungary, Romania and Slovakia," J. Environ. Monit., vol. 8, no. 1, pp. 203-208, 2006.

[4] R. C. Cheng, S. Liang, H. C. Wang, and M. D. Beuhler, "Enhanced coagulation for arsenic removal," J. / Am. Water Work. Assoc., vol. 86, no. 9, pp. 79-90, 1994.

[5] D. Mohan and C. U. Pittman, "Arsenic removal from water/wastewater using adsorbents-A critical review," J. Hazard. Mater., vol. 142, no. 1-2, pp. 1-53, 2007.

[6] W. S. Wan Ngah, L. C. Teong, and M. A. K. M. Hanafiah, "Adsorption of dyes and heavy metal ions by chitosan composites: A review," Carbohydr. Polym., vol. 83, no. 4, pp. 1446-1456, 2011.

[7] H. Luan, B. Teychene, and H. Huang, "Efficient removal of $\mathrm{As}(\mathrm{III})$ by $\mathrm{Cu}$ nanoparticles intercalated in carbon nanotube membranes for drinking water treatment," Chem. Eng. J., vol. 355, no. August 2018, pp. 341-350, 2019.

[8] J. F. A. Silva, N. S. Graça, A. M. Ribeiro, and A. E. Rodrigues, "Electrocoagulation process for the removal of co-existent fluoride, arsenic and iron from contaminated drinking water," Sep. Purif. Technol., vol. 197, no. September 2017, pp. 237-243, 2018.

[9] V. L. Dhadge, C. R. Medhi, M. Changmai, and M. K. Purkait, "House hold unit for the treatment of fluoride, iron, arsenic and microorganism contaminated drinking water," Chemosphere, vol. 199, pp. 728-736, 2018.

[10] Z. Wang, X. Shen, M. Jing, and C. Li, "Enhanced arsenic removal from drinking water by $\mathrm{FeOOH} /-\mathrm{Al} 2 \mathrm{O} 3$ granules," J. Alloys Compd., vol. 735, pp. 1620-1628, 2018.

[11] F. Ahmed, "Arsenic Mitigation Technologies in South and East Asia," East Asia, p. 44, 2006.

[12] S. Mandal, M. K. Sahu, and R. K. Patel, "Adsorption studies of arsenic(III) removal from water by zirconium polyacrylamide hybrid material (ZrPACM-43)," Water Resour. Ind., vol. 4, pp. 51-67, 2013. 
[13] A. A. Lewinsky, Hazardous materials and wastewater: treatment, removal and analysis. 2007.

[14] B. Das, "Calcareous Soil as a New Adsorbent to Remove Lead from Aqueous Solution: Equilibrium , Kinetic and Thermodynamic Study Abstract: 2 . 1 Preparation of the Synthetic Sample: 2 . 4 Batch Sorption Experiment:," Univers. J. Environ. Res. Technol., vol. 1, no. 4, pp. 515-530, 2011.

[15] B. Rajesh Kannan, R. , Rajasimman, M. , Rajamohan, N. and Sivaprakash, "Equilibrium and Kinetic Studies on Sorption of Malachite Green using Hydrilla Verticillata Biomass," Int. J. Environ. Res, vol. 4, no. 4, pp. 817-824, 2005.

[16] L. Dong, P. V. Zinin, J. P. Cowen, and L. C. Ming, "Iron coated pottery granules for arsenic removal from drinking water," J. Hazard. Mater., vol. 168, no. 2-3, pp. 626-632, 2009.

[17] M. M. Benjamin, R. S. Sletten, R. P. Bailey, and T. Bennett, "Sorption and filtration of metals using iron-oxidecoated sand," Water Res., vol. 30, no. 11, pp. 2609-2620, 1996. 